\section{An urgent referral of a suspected case of child abuse}

\author{
S. T. McDonnell ${ }^{1}$ and I. C. Mackie ${ }^{2}$
}

IN BRIEF
- Highlights the importance of a thorough
history and examination.
- Emphasises the importance of following
local protocols.
Directs the reader to important learning
resources.

A 3-year-old girl was referred to the unit of paediatric dentistry by her dentist with regard to a metal nail lodged in the alveolus above 53. The child's mother was making allegations of child abuse against the child's father. This case describes the processes that were followed in order to reach a diagnosis and safeguard the child. This case also highlights the need to fully investigate all cases of reported or suspected abuse and to follow proper procedures to ensure the interests of the victim and accused are protected.

\section{INTRODUCTION}

The dental team is in a good position to recognise abuse and neglect. Families may attend a particular practice over a number of years and concerns may build up over a period of time or may be the result of a single 'emergency' visit. ${ }^{1}$

Abuse or neglect may present as signs and symptoms, observations of a child's behaviour, observation of parent-child interaction or through a direct allegation made by the parent, child or some other person. ${ }^{1}$

In most cases the perpetrator of abuse is the child's parent., ${ }^{2,3}$ Biological parents are implicated almost equally ${ }^{2,3}$ but rarely collaborate. One parent is usually the abuser whilst the other parent assumes a passive position allowing the abuse to continue. ${ }^{4}$

In the UK it has been reported that $45 \%$ of child victims are aged four years or under. $^{3}$ Fifty-nine percent of physically abused children had orofacial signs of abuse that would be easily

\footnotetext{
${ }^{1 * 2}, 2$ Unit of Paediatric Dentistry, University Dental Hospital of Manchester, Higher Cambridge Street, Manchester, M15 6FH

${ }^{*}$ Correspondence to: Dr Sinead McDonnell Email: sinead.mcdonnell@manchester.ac.uk
}

visible to a dental practitioner. ${ }^{3}$ The prevalence of intraoral injuries, however, is relatively low. The prevalence of intraoral injuries has been reported as between $0.5 \%$ and $33.3 \% .^{3,5-8}$ However, in most cases these children were not examined by a dentist and it may be that the prevalence of intraoral injuries is underestimated. ${ }^{8}$

Research has shown that many dentists have never received child protection training and do not know what to do if concerned that a child in their care is being abused..$^{9,10}$ They want to be sure they have made the right diagnosis before taking action and are also concerned that their actions may lead to removal of the child with serious consequences for the family. For 52\% of general dental practitioners in Scotland the latter was a barrier to referral of suspected cases of child abuse. ${ }^{10}$ In reality, however, less than $50 \%$ of children investigated for suspected abuse end up on the child protection register. ${ }^{11}$ Less than $1 \%$ of referrals are thought to progress to judicial proceedings. ${ }^{12}$

This paper reports a case of suspected child abuse in a 3-year-old child.

\section{CASE REPORT}

A dentist telephoned the Unit of Paediatric Dentistry and spoke to the oncall consultant. He was requesting an urgent referral. A mother had presented with her 3-year-old child at his surgery earlier that day as an emergency. The mother alleged that the child's father was causing her harm and had driven a nail into her child's gum above 53. The mother requested removal of the nail and a copy of the treatment records so that these could be used in court. The child's parents were undergoing a formal separation. The dentist was advised to send the patient to the dental hospital immediately. Meanwhile we contacted our trust's child protection team.

The child presented at the Unit of Paediatric Dentistry, University Dental Hospital of Manchester accompanied by her mother. The child was happy, chatty, playful and well presented. The mother reported that she had noticed the nail in the child's gum two or three days ago but was not sure how long it had been there. The child's mother alleged the nail had been pushed into the gum by the child's father. The mother had already contacted her solicitor. The solicitor recommended that she attend the dentist before contacting a social worker. The mother requested a copy of all dental records so that they could be used in court.

The child had no relevant medical history. Social history revealed the child's parents had separated five months ago. Further questioning revealed the child 


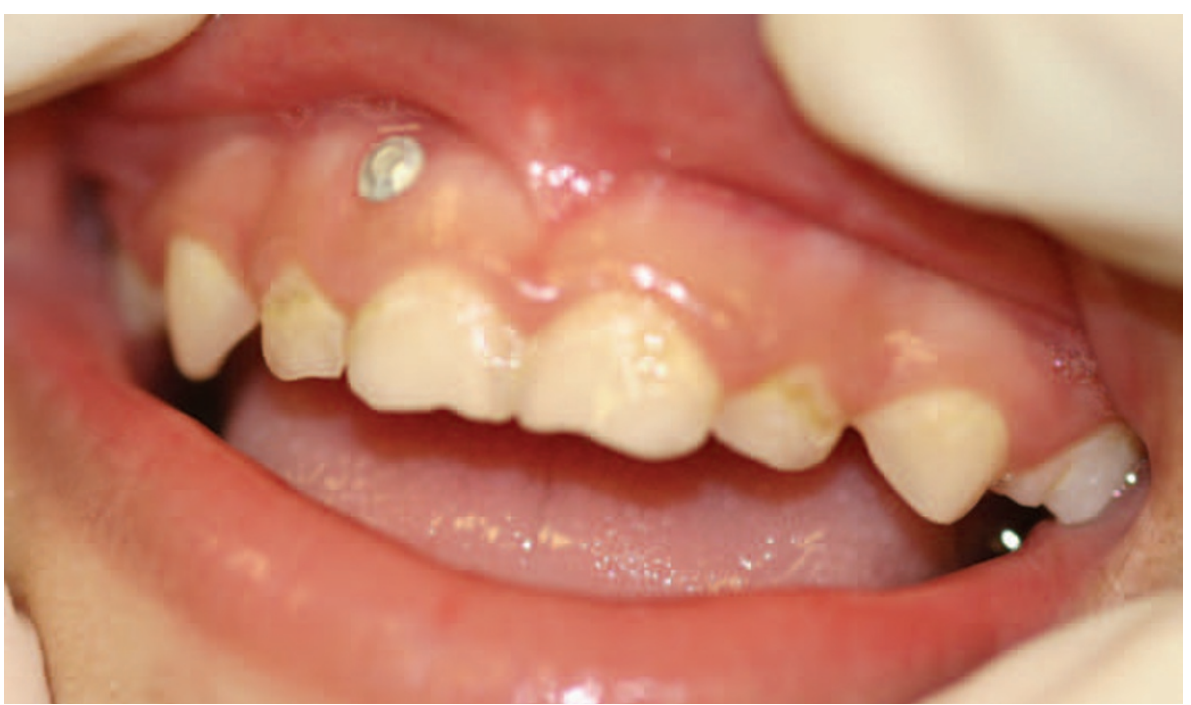

Fig. 1 Intraoral photograph of maxillary dentition. Note the silver disc $2.5 \mathrm{~mm}$ in diameter in the 51,52 region $2.5 \mathrm{~mm}$ from the gingival margin on the attached gingivae

had had no known contact with her father during the last five months. The mother suggested he may have had contact with the child when the child was collected from a crèche by a friend two months previously. The child was registered with a dentist and had attended once 12-18 months ago. She had no previous dental treatment. Her mother reported that she brushed her child's teeth twice a day with fluoride toothpaste. She had one sister aged seven months.

The child was very co-operative. On examination she had a well cared for mouth. Her oral hygiene was good with no evidence of gingival inflammation and the full complement of her primary dentition was present. There was early decalcification buccal to 52 and 62 . There was a silver disc $2.5 \mathrm{~mm}$ in diameter in the 51, 52 region $2.5 \mathrm{~mm}$ above the gingival margin on the attached gingivae. The disc resembled the head of a small metal nail. It could not be dislodged with gentle finger pressure. There was no surrounding inflammation or necrosis (Fig. 1). Clinical intraoral photographs were taken with the mother's consent.

An upper anterior occlusal and right lateral oblique radiographs were requested. The child's cooperation for these procedures was limited. The upper anterior occlusal was of no diagnostic value. The right lateral oblique did not show any radiopacity consistent with a metal nail (Fig. 2). It was concluded that the disc was probably aluminium.
Removal of the disc was attempted using an excavator which was slipped under the periphery of the disc dislodging it with ease. The gingival tissues underneath were healthy. Closer examination of the disc revealed that it had a concave undersurface enabling it to adhere to the gingivae by suction effect. It resembled a sequin and it was concluded it may have come from a piece of clothing. No abuse was suspected. The child's mother was reassured. The child was discharged. No further child protection action was required and the case was therefore not referred on to social services for further assessment.

Later that day a police officer from the Child Protection Unit contacted us to enquire about the case. They had been contacted by the trust child protection team. The child's details had been given to the police officer. The police officer was informed that history and examination of the child did not indicate that she had been abused as suspected and no further child protection action was required. There was no criminal case to answer.

\section{DISCUSSION}

The referring dentist in this case did not feel confident in dealing with the case himself. This may have been due to lack of training or fear of initiating a process when there was no case to answer. The responsibility for making a diagnosis however is always shared by a

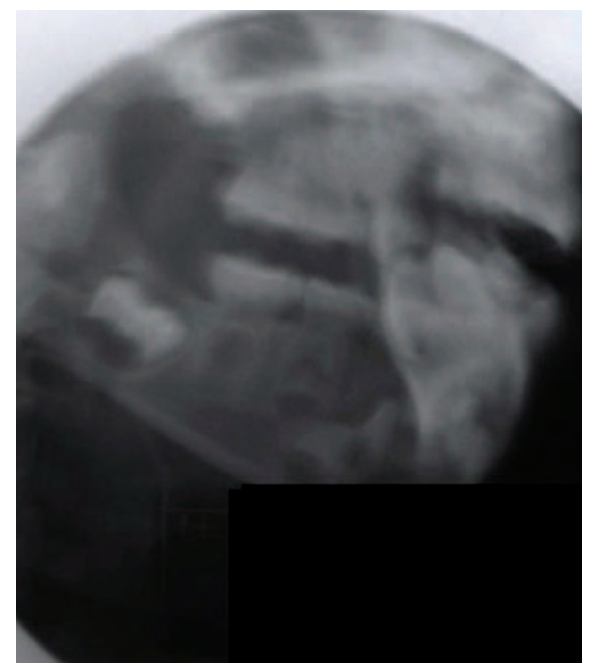

Fig. 2 Right lateral oblique radiograph. No evidence of any radiopacity consistent with a metal nail 53 region

multi-agency team. It is important that dentists share their concerns with the team as they may contribute a vital piece of information required to initiate the process for effective protection of the child. It is also important that there is no delay as this may put the child at further risk. The steps to take are published in every area by the local Safeguarding Children Board. A 'fast response tool' can be found in the Department of Health educational resource for dental teams working in primary care in England. Child protection and the dental team: an introduction to safeguarding children in dental practice ${ }^{13}$ has been published as an open access website (www.cpdt.org. uk) and an equivalent booklet. It also provides a training resource to update knowledge on child protection and advice on preparing your dental practice to safeguard children.

In this case the dentist acted appropriately in discussing the case with a more experienced colleague (Consultant in Paediatric Dentistry) and referring the child to them immediately for assessment. As soon as we became aware of the case local policies and procedures were consulted and followed. The agencies communicated with each other until it became clear there was no case to answer and no further child protection action was required. In hindsight perhaps we should not have made contact with the child protection team until we had taken the history from the child's mother and examined the child 
ourselves. In this case, however, the child had already been seen by her dentist and the assumption was made that the diagnosis of the referring dentist was correct. Contact with the child protection team at an early stage was therefore made in the child's best interest.

Doubts about the alleged abuse by the child's father were raised early on. During the history it became apparent that it was unlikely that the father had access to the child since the parents separated five months previously. It was also unlikely that the mother would not have noticed a nail that had been there for some time until just two or three days before presentation if she was, as claimed, brushing her child's teeth twice a day. It was also apparent that the mother was very keen to collect any information which might assist her court case in relation to separation from her husband.

\section{SUMMARY/CONCLUSION}

In this case it was concluded that there was no abuse. This case highlights the importance of having all alleged cases of child abuse investigated and documented by the appropriate healthcare professionals. This not only safeguards the interests of the alleged abused but also as in this case those of the accused.

1. Harris J C, Sidebotham P D, Welbury R R. Safeguarding children in dental practice. Dent Update 2007; 34: 508-517.

2. Kenney I P Clark D H Child abuse. In Clark D H (ed). Practical forensic odontology. pp 139. Oxford: Butterworth-Heinemann Ltd, 1992.

3. Cairns A M, Mok J Y O, Welbury R R. Injuries to the head, face, mouth and neck in physically abused children in a community setting. Int J Paediatr Dent 2005; 15: 310-318.

4. Gallo L G. Child abuse: who is involved? N Y State Dent J 1983; 49: 77-78.

5. Becker D B, Needleman H L, Kotelchuck M. Child abuse and dentistry: oro-facial trauma and its recognition by dentists. J Am Dent Assoc 1978; 97: 24-28.

6. Jessee SA. Physical manifestations of child abuse to the head, face and mouth: a hospital survey. ASDC J Dent Child 1995; 62: 245-249.

7. Da Fonseca M A, Feigal R J, ten Bensel R W. Dental aspects of 1248 cases of child maltreatment on file at a major county hospital. Pediatr Dent 1992; 14: 152-157.

8. Naidoo S. A profile of the orofacial injuries in child physical abuse at a children's hospital. Child Abuse Neg/ 2000; 24: 521-534.

9. Welbury R R, Macaskill S G, Murphy J M et al. General dental practitioners perception of their role within child protection: a qualitative study. Eur J Paediatr Dent 2003; 2: 89-95.

10. Cairns A M, Mok J Y Q, Welbury R R. The dental practitioner and child protection in Scotland. $\mathrm{Br}$ Dent J 2005; 199: 517-520.

11. Department for Education and Skills. Statistics of Education: Referrals, Assessments and Children and Young people on Child Protection Registers: Year ending 31 March 2004. London: The Stationary Office, 2005. www.dfes.gov.uk.

12. Wynne J, Speight N. Response to 'who is failing abused and neglected children?' Arch Dis Child 2001; 85: 300-302.

13. Harris J, Sidebotham P, Welbury R et al. Child Protection and the Dental Team: An Introduction to Safeguarding Children in Dental Practice. Sheffield: COPDEND, 2006. www.cpdt.org.uk. 